\title{
Sensitivity, Specificity, Negative and Positive Predictive Values of Adenosine Deaminase in Patients of Tubercular and Non-Tubercular Serosal Effusion in India
}

\author{
Bharat Kumar Gupta ${ }^{\mathrm{a}, \mathrm{c}}$, Vinay Bharat ${ }^{\mathrm{b}}$, Debapriya Bandyopadhyay ${ }^{\mathrm{a}}$
}

\begin{abstract}
Background: In India, tuberculosis is an endemic disease. Delay in diagnosis results in poor prognosis and fast spread of the disease. The objective of the present study is to look for an effective and acceptable diagnostic test, which may be helpful to initiate early treatment to improve prognosis and reduce spread.
\end{abstract}

Methods: Three hundred and thirty patients with pleural, ascitic, meningeal and synovial effusion were selected and divided depending upon the etiology and the involvement of serosal membranes. Serosal aspirated fluid was subjected to biochemical tests and adenosine deaminase estimation. Cutoff taken is above 40 for pleural, peritoneal or synovial fluid and above 10 for CSF.

Results: In cases of pulmonary and extra-pulmonary disease, sensitivity was $92.80 \%$ and $94.29 \%$; specificity $90.00 \%$ and $92.16 \%$; positive predictive value $92.86 \%$ and $89.00 \%$; and negative predictive value $90.00 \%$ and $95.92 \%$ respectively.

Conclusions: Adenosine deaminase estimation is not only a fairly sensitive and specific test (more than 90\%), helpful in differentiating tubercular from non-tubercular etiology both in pulmonary and extra-pulmonary disease, but is also simple, inexpensive and rapid. For this reason this test may help in early diagnosis, improve the prognosis and reduce spread of disease and sequlae.

Keywords: Adenosine deaminase; Serosal effusion; Tubercular; Non-tubercular; Pulmonary; Extra-pulmonary

\footnotetext{
Manuscript accepted for publication April 14, 2010

${ }^{a}$ Department of Biochemistry, Subharti Medical College, S. V. S.

University, Meerut, India

${ }^{\mathrm{b}}$ Department of Pathology, Subharti Medical College, S. V. S.

University, Meerut, India

${ }^{\mathrm{c}}$ Corresponding author: 69/70 New Market, Begum Bridge,

Meerut-250001, India. Email: chotubharat@yahoo.com
}

doi:10.4021/jocmr2010.05.289w

\section{Introduction}

Tuberculosis is one of the commonest chronic infectious diseases, which is highly endemic in India and five lakh patients die every year [1]. It usually affects lungs but cases of extrapulmonary tuberculosis are not rare. Delay in diagnosis and in initiating treatment results in poor prognosis and sequlae in up to $25 \%$ of cases [2]. In a large percentage of cases, involvement of pleura, peritoneum, meninges and synovial membranes is also common. Pulmonary Tuberculosis (TB) can be confirmed by sputum examination and diagnosed easily, but diagnosing extra-Pulmonary TB becomes frequently difficult since the specificity and sensitivity of non-invasive methods is very low.

When aspirated serosal fluids were analyzed for direct evidence of disease, acid fast bacilli (AFB) positivity rate is very low and this process is time consuming also. AFB culture is expensive and requires long incubation period and is positive in less than $25 \%$ cases (Rafae Laniado-Laborin). Direct examination of pleural fluid by Zeihl-Neelsen staining requires bacillary densities of $10,000 / \mathrm{mL}$ [3] and, therefore, detects AFB in less than $10 \%$ of cases. Elisa, PCR, Tub IgG and IgM, and interferon are very expensive tests and beyond the reach of the general population in poor countries.

Adenosine deaminase (ADA) is an enzyme in the purine salvage pathway that catalyzes the conversion of adenosine and deoxyadenosine to inosine and deoxyinosine with the release of ammonia. It plays important role in differentiating lymphoid cells and is present in abundance in active Tlymphocytes whose concentration is inversely proportional to the degree of differentiation [4]. Its levels are ten times higher in T-lymphocytes than in erythrocytes. The enzyme activity increases during mitogenic and antigenic responses of lymphocytes, and T-lymphocyte blastogenesis can be inhibited by inhibitors of ADA. Likewise, a deficiency of adenosine deaminase is associated with severe defects in the cell-mediated and humoral arms of the immune system, predisposing the patient to opportunistic infections.

Tuberculous effusion is the result of a cell-mediated immune response to the presence of Mycobacterium tuberculii and is characterized by the accumulation of activated T-lym- 
phocytes and macrophages. Elevated levels of ADA in tuberculous effusions have been noted by several authors. ADA is now being recognized as a marker of cell-mediated immunity particularly as a marker of T-lymphocyte activation.

Since ADA is increased in TB effusions and is an easy little-invasive investigation, it is frequently considered as a diagnostic aid in such cases with a sensitivity of $90-100 \%$ and specificity $89-100 \%$. ADA levels have also been considered by several researchers to differentiate tubercular disease from non-tubercular [5-7]. The aim of the present study is to: (1) propose a simple, rapid and cost effective test for diagnosing tuberculosis and differentiating it from other etiologies both in pulmonary and extra-pulmonary disease with fairly good accuracy; (2) initiate early anti-tubercular treatment to improve prognosis and reduce spread and sequlae.

\section{Methods}

Patients attending out and in-patient departments of chest and respiratory diseases, medicine, pediatrics and orthopedic surgery of Subharti Medical College and its rural and urban health Centers at Sarawani, Mahalwala, Khajoori and Multan Nagar at distant places in district Meerut of India from January 2007 to October 2009 with pleural, peritoneal, meningeal and synovial tubercular disease with serosal effusion were taken.

The project was approved by the ethical committee of our institution. After taking informed consent, 330 such patients were included in the present study. Detailed clinical history, physical examination, investigations, for example, $\mathrm{Hb}$, T/DLC, ESR, GBP, CBC, SGOT, SGPT, PPD test and $\mathrm{X}$-ray/ultrasound were done in all the cases. AFB in the sputum/fluid, AFB culture, ECG, cytology and biopsy with its
Table 1. Reference Values of ADA in Various Body Fluids (U/L)

\begin{tabular}{lll}
\hline Type of Fluid & Negative & Positive \\
\hline $\begin{array}{l}\text { Serum/plasma/Pleural/ } \\
\text { Ascitic/synovial Fluids }\end{array}$ & 40 or $<40$ & $>40$ \\
CSF & 10 or $<10$ & $>10$ \\
\hline
\end{tabular}

histopathological examination were done in selective cases. Effusions were aspirated and fluid was subjected to the biochemical examination and ADA activity testing. Any other relevant/necessary/required investigations were also carried out in specific case.

Presence of first or more than one of the following criteria was adopted to label a case as tuberculous: (1) Bacteriological confirmation of presence of Mycobacterium tuberculosis (direct smear or culture or histological finding); (2) Histopathology finding of caseous granulomas; (3) Radiological findings consistent with TB; (4) Clinical presentation consistent with TB with exclusion of other clinical considerations; (5) Definite clinical and radiological improvement in two months on administration of exclusive anti-tuberculosis treatment; (6) History of contact with current disease and positive reaction (more than $20 \mathrm{~mm}$ induration) to the $5 \mathrm{tu}$ berculin unit (TU) purified protein derivative (PPD).

Following precautions were taken while performing the ADA and other routine tests on the fluids: (1) Fluids were collected in sterile containers; (2) Detailed gross examination which included volume, color, turbidity, any flakes etc. was noted; (3) Microscopic examination of the fluid was done for total and differential leukocyte count and also for

Table 2. Table Showing Distribution of Cases According to the Initial Set Criteria

\begin{tabular}{llll}
\hline Type of Disease & Aspirated Fluid & $\begin{array}{l}\text { Etiology; } \\
\text { According to Set Criteria }\end{array}$ & Number of Cases \\
\hline 1. Pulmonary & Pleural $(\mathrm{n}=72)$ & Tuberculous & 42 \\
& & Non tuberculous & 30 \\
2. Extra-Pulmonary & Ascitic/Peritoneal & Tuberculous & 36 \\
& $(\mathrm{n}=108)$ & Non tuberculous & 72 \\
& CSF $(\mathrm{n}=120)$ & Tuberculous & 54 \\
& & Non tuberculous & 66 \\
& Synovial $(\mathrm{n}=30)$ & Tuberculous & 21 \\
& & Non tuberculous & 09 \\
\hline
\end{tabular}


Table 3. Table Showing ADA and AFB Positivity in Tubercular Group

\begin{tabular}{llll}
\hline $\begin{array}{l}\text { Type of Tubercular } \\
\text { Disease }\end{array}$ & Aspirated Fluid & $\begin{array}{l}\text { Etiology; No. of Tubercular } \\
\text { Cases According to Set Criteria }\end{array}$ & $\begin{array}{l}\text { AFB Positive } \\
\text { Cases }\end{array}$ \\
\hline Pulmonary $(\mathrm{n}=42)$ & Pleural $(\mathrm{n}=72)$ & 42 & 14 \\
Extra-Pulmonary $(\mathrm{n}=111)$ & Ascitic/Peritoneal $(\mathrm{n}=108)$ & 36 & 09 \\
& CSF $(\mathrm{n}=120)$ & 54 & nil \\
& Synovial $(\mathrm{n}=30)$ & 21 & nil \\
& & 153 & 23 \\
\hline
\end{tabular}

any other abnormal cell; (4) Fluid was centrifuged, slide prepared from the residue, stained by $\mathrm{Z}-\mathrm{N}$ staining and examined for AFB microscopically; (5) ADA test was done by Guisti and Galanti method [8] on the same day, the fluid was received. If a delay in performing the test was anticipated, the fluid was kept in the refrigerator at $2-4{ }^{\circ} \mathrm{C}$ after adding glycerol to it, to avoid decrease in ADA level with the lapse of time at ambient temperature.

In case of readings beyond the linearity of the assay system, the test was repeated with appropriate dilutions of the samples and the result was calculated considering the dilution factor. In case of turbid effusions the fluids were centrifuged and the test was performed from the clear supernatant. And if the fluid was still found to be turbid, it was excluded from the study.

Reference values, as follows, were taken as per the recommendations of Microxpress, a division of Tulip Diagnostics (P) Ltd. India, of which chemicals and re- agents were used. ADA levels above $40 \mathrm{U} / \mathrm{L}$ were taken as positive in samples from pleural, ascitic or synovial fluid while ADA levels above $10 \mathrm{U} / \mathrm{L}$ were taken as positive in CSF (Table 1).

\section{Results}

Out of 330 aspirated samples, 72 were pulmonary (Pleural) and 258 were extra-pulmonary serosal effusions. Amongst extra-pulmonary, 108 were peritoneal (Ascitic), 120 were cerebrospinal and 30 were synovial fluids. These samples were divided according to the criteria set for tuberculosis: 42 samples were tubercular while 30 were non-tuberculous amongst pulmonary disease and amongst extra-pulmonary; 36 samples were tubercular while 72 were non-tubercular in abdominal disease; 54 samples were tubercular while 66 were non-tubercular in cerebrospinal disease; and 21 samples were tubercular while 9 were non-tubercular in muscu-

Table 4. Table Showing Range of ADA With Median Corresponding to Etiology

\begin{tabular}{llll}
\hline Type of Fluid & Cut Off & Range U/L & Median \\
\hline Pleural & $>40$ & $40.4-136$ & 88 \\
& $\leq 40$ & $4.8-38$ & 21.5 \\
Ascitic/Peritoneal & $>40$ & $48-180$ & 110 \\
& $\leq 40$ & $3.3-40$ & 16 \\
Synovial & $>40$ & $46-156$ & 88 \\
& $\leq 40$ & $25-32.6$ & 27.2 \\
CSF & $>10$ & $10.2-110$ & 24 \\
& $\leq 10$ & $2-10$ & 6.4
\end{tabular}


Table 5. Sensitivity, Specificity, Negative and Positive Predictive Values of ADA Estimation in Different Groups

\begin{tabular}{|c|c|c|c|c|c|c|c|c|}
\hline $\begin{array}{l}\text { Type of } \\
\text { Disease }\end{array}$ & $\begin{array}{l}\text { Aspirated } \\
\text { Fluid }\end{array}$ & $\begin{array}{l}\text { Etiology } \\
\text { According to } \\
\text { Set Criteria }\end{array}$ & $\begin{array}{l}\text { Cut Off } \\
\text { Value of } \\
\text { ADA }\end{array}$ & $\begin{array}{l}\text { Number } \\
\text { of True } \\
\text { Positive/ } \\
\text { Negative } \\
\text { Cases }\end{array}$ & $\begin{array}{l}\text { Sensitivity } \\
\%\end{array}$ & $\begin{array}{l}\text { Specificity } \\
\%\end{array}$ & $\begin{array}{l}\text { Positive } \\
\text { Predictive } \\
\text { Value \% }\end{array}$ & $\begin{array}{l}\text { Negative } \\
\text { Predictive } \\
\text { Value \% }\end{array}$ \\
\hline \multirow[t]{2}{*}{$\begin{array}{l}\text { Pulmonary } \\
(\mathrm{n}=72)\end{array}$} & $\begin{array}{l}\text { Pleural } \\
(\mathrm{n}=72)\end{array}$ & $\begin{array}{l}\text { Tuberculous } \\
(\mathrm{n}=42)\end{array}$ & $>40$ & 39 & 92.80 & 90.00 & 92.86 & 90.00 \\
\hline & & $\begin{array}{l}\text { Non-tuberculous } \\
(\mathrm{n}=30)\end{array}$ & $\leq 40$ & 27 & & & & \\
\hline \multirow{8}{*}{$\begin{array}{l}\text { Extra- } \\
\text { Pulmonary } \\
(\mathrm{n}=258)\end{array}$} & $\begin{array}{l}\text { Over all } \\
\text { includes; }\end{array}$ & $\begin{array}{l}\text { Tuberculous } \\
(\mathrm{n}=111)\end{array}$ & $>40 / 10$ & 99 & 94.29 & 92.16 & 89.00 & 95.92 \\
\hline & & $\begin{array}{l}\text { Non-tuberculous } \\
(\mathrm{n}=147)\end{array}$ & $\leq 40 / 10$ & 141 & & & & \\
\hline & $\begin{array}{l}\text { Ascitic } \\
(\mathrm{n}=108)\end{array}$ & $\begin{array}{l}\text { Tuberculous } \\
(\mathrm{n}=36)\end{array}$ & $>40$ & 33 & 100 & 96 & 91.67 & 100.00 \\
\hline & & $\begin{array}{l}\text { Non-tuberculous } \\
(\mathrm{n}=72)\end{array}$ & $\leq 40$ & 72 & & & & \\
\hline & $\begin{array}{l}\text { Synovial } \\
(\mathrm{n}=30)\end{array}$ & $\begin{array}{l}\text { Tuberculous } \\
(\mathrm{n}=21)\end{array}$ & $>40$ & 18 & 85.71 & 66.67 & 85.71 & 66.67 \\
\hline & & $\begin{array}{l}\text { Non-tuberculous } \\
(\mathrm{n}=09)\end{array}$ & $\leq 40$ & 06 & & & & \\
\hline & $\begin{array}{l}\text { CSF } \\
(n=120)\end{array}$ & $\begin{array}{l}\text { Tuberculous } \\
(\mathrm{n}=54)\end{array}$ & $>10$ & 48 & 84.12 & 91.30 & 88.89 & 95.46 \\
\hline & & $\begin{array}{l}\text { Non-tuberculous } \\
(\mathrm{n}=66)\end{array}$ & $\leq 10$ & 63 & & & & \\
\hline
\end{tabular}

loskeletal disease (Table 2).

Only 14/42 (33.34\%) amongst pulmonary tubercular disease and 9/36 (25\%) amongst peritoneal tubercular disease were confirmed by direct evidence of AFB while none in synovial fluid and CSF showed the evidence of AFB positivity. In the present study, only $23 / 153(15.03 \%)$ patients could be conformed by evidence of AFB (Table 3 ).

ADA levels in tubercular pleural fluid ranged between 40.4 and 136 with a median value of 88 while in non-tubercular pleural effusions it ranged between 4.8 and 38 with a median value of 21.5. ADA levels in tubercular ascitis ranged between 48 and 180 with a median level of 110 , and in non- tubercular ascitis it ranged between 3.3 and 40 with a median value of 16. ADA levels in tubercular joint effusions ranged between 46 and 156 with a median level of 88 , and in non- tubercular joint effusions it ranged between 25 and 32.6 with a median value of 27.2. ADA levels in tubercular CSF ranged between 10.2 and 110 with median value of 24 , and in non-tubercular CSF value was found to be between 2 and 10 with a median value of 6.4 (Table 4).

In the present study amongst pulmonary tubercular disease samples, 39/42 had ADA levels above $40 \mathrm{U} / \mathrm{L}$, while 27/30 of non-tuberculous pleural fluid had ADA levels no more than $40 \mathrm{U} / \mathrm{L}$. In extra-pulmonary disease, tubercular samples 33/36 of ascitic fluid, 18/21 of synovial fluid and 48/54 of CSF had ADA levels above the cutoff, while in non-tubercular samples 72/72 of ascitic fluid, 6/9 of synovial fluid and 63/66 of CSF had values below the cutoff (Table 5).

In extra-pulmonary disease, tubercular samples 99/111 had ADA levels above the cutoff, while in non-tubercular samples 141/147 had below the cutoff level (Table 5). Sensitivity, specificity, positive predictive values and negative predictive values were calculated using standard formulae.

In our study, in cases with pleuropulmonary disease sensitivity was found to be $92.80 \%$, specificity was $90.00 \%$, positive predictive value $92.86 \%$ and negative predictive value $90.00 \%$. In cases of extra-pulmonary disease with the involvement of peritoneum, sensitivity was found to be 
$100.00 \%$, specificity was $96.00 \%$, positive predictive value $91.67 \%$ and negative predictive value $100.00 \%$; in cases of musculoskeletal disease, sensitivity was found to be $85.71 \%$, specificity was $66.67 \%$, positive predictive value $85.71 \%$ and negative predictive value $66.67 \%$; while in cases of meningeal involvement, sensitivity was found to be $84.12 \%$, specificity was $91.30 \%$, positive predictive value $88.89 \%$ and negative predictive value $95.46 \%$ (Table 5).

In extra-pulmonary disease, the overall sensitivity was found to be $94.29 \%$, specificity was $92.16 \%$, and positive predictive value $89.00 \%$ and negative predictive value 95.92\% (Table 5).

\section{Discussion}

Demonstration of AFB, culture, CT and MRI scan etc. are the various means to confirm the etiology of tuberculosis but visualization of AFB in direct smears or in cultures is usually difficult [9] and in most cases negative. Newer methods such as those involving the amplification of bacterial DNA by the PCR and comparable systems, are not available for widespread use in the developing countries. Routine laboratory findings may not be helpful to differentiate tuberculous etiology from other causes.

Cell-mediated response is the predominant form of immune response to tuberculous infection, while both cell-mediated and humoral immune responses are elicited by most non-tuberculous infections in human body. Thus ADA activity, a marker of T-cell activation and cell-mediated immune response can help differentiate tubercular etiology from nontubercular.

Piras et al were first to report high ADA in tubercular pleural effusion [10]. Subsequently several workers explored its efficacy in the diagnosis of tuberculosis [11] and determined that pleural fluid ADA level less than $40 \mathrm{U} / \mathrm{L}$ virtually excludes the diagnosis of tuberculosis [3]. Meta-analysis of studies conducted between 1966 and 1999 concluded that the test performance was reasonably good [12] (sensitivity range $47.1-100 \%$, and specificity $0-100 \%$ ) in diagnosing tuberculosis etiology in pleural effusion.

Ocana et al in 1983 [11] and Valdes et al in 1993 [13] and 1996 [14, 15] reported 100\% sensitivity and specificity, positive predictive value and negative predictive value in larger sample size studies.

Perez [16] reported the sensitivity and specificity for ADA to be 77 - 100\% (average, 93.3\%) and 81 - 97\% (Average, $91.3 \%$ ) respectively on summarizing eleven studies, and Chen et al [17] reported the sensitivity and specificity for ADA as $79-100 \%$ (average, 88.6\%) and 80.5 - 96\% (average, $85.4 \%$ ) respectively on summarizing the results of eight studies.

In 2007, a systematic review of ADA by the NGS Health Technology Assessment Programme concluded that there is no evidence to support the use of ADA tests for the diagnosis of pulmonary TB. However, there is considerable evidence to support their use in pleural fluid samples for diagnosis of pleural TB, where sensitivity was very high, and to a slightly lesser extent for TB meningitis. In both pleural TB and TB meningitis, ADA tests had higher sensitivity than any other tests [18].

CSF-ADA estimation was reported to be useful in diagnosing TBM and can differentiate TBM from other neurological disorders [19]. CSF-ADA estimation is a useful method to differentiate TBM from aseptic meningitis [5]. Other researchers have also observed the usefulness of ADA activity in the diagnosis of tubercular disease [20, 21].

Other causes of increase in ADA activity include bacterial infections, rheumatic disease and lymphoproliferative disorders. This article reviews ADA estimation as an effective diagnostic criterion for tuberculous and non-tuberculous disease in pleural, ascitic, synovial fluids and CSF.

In our study, in extra-pulmonary disease with the involvement of peritoneum, sensitivity was found to be $100.00 \%$, specificity $96.00 \%$, positive predictive value $91.67 \%$ and negative predictive value $100.00 \%$; in cases of involvement of musculo-skeletal disease, sensitivity was found to be $85.71 \%$, specificity $66.67 \%$, positive predictive value $85.71 \%$ and negative predictive value $66.67 \%$; while in cases of meningeal involvement, sensitivity was found to be $84.12 \%$, specificity $91.30 \%$, positive predictive value $88.89 \%$ and negative predictive value $95.46 \%$.

In extra-pulmonary disease, our overall sensitivity was found to be $94.29 \%$, specificity $92.16 \%$, positive predictive value $89.00 \%$ and negative predictive value $95.92 \%$; and in pulmonary disease, sensitivity was found to be $92.80 \%$, specificity $90.00 \%$, positive predictive value $92.86 \%$ and negative predictive value $90.00 \%$.

We have observed a statistically significant difference in ADA levels of tubercular and non-tuberculous etiology $(\mathrm{p}<$ 0.01 ). Results of our study indicated that ADA levels in the aspirated fluid are of considerable value in differentiating between tubercular and non-tubercular disease with fairly high accuracy and sensitivity at the taken cutoff.

In $\mathrm{TB}$ endemic countries like India, patients with raised ADA levels could be a signal for tuberculosis where AFB positivity is low. This may help in early diagnosis and institution of ATT, thus can significantly alter not only the spread but also the progress and prognosis of TB in our country. Our study is a unique study debating the significance of ADA estimation in diverse form of extra-pulmonary TB including musculoskeletal tuberculosis.

ADA estimation can also be of considerable help in western countries where other causes of lymphocyte rich effusions should be considered like coccidiodomycosis and histoplasmosis. ADA levels, in these cases, are found to be below the cutoff value and thus save the patient from unnecessary anti-tubercular treatment. 
It can be concluded that ADA estimation is not only effective but also simple, inexpensive, quick to perform test; it can be used as an alternative to biopsy/culture and also as a guide for further sophisticated investigations. This test may find a place as a routine investigation in the coming days for early detection of tuberculosis where other means are expensive.

In conclusion, ADA estimation is not only a fairly sensitive and specific test (more than 90\%), helpful in differentiating tubercular from non-tubercular etiology both in pulmonary and extra-pulmonary disease, but is also simple, inexpensive and rapid. For this reason this test may help in early diagnosis, improve the prognosis and reduce spread of disease and sequlae.

\section{References}

1. Tandon, P.N. Neurotuberculosis: Clinical aspects. Neurology in Tripica. Chopra J.S. and Sawhney. I.M.S. ed Churchill Livingstone Ltd.;1999,p.358-89.

2. Gecia-monco J.C. CNS Tuberculosis. Neurologic clinics. Marra C.M. ed.;1999, 17(4), p.737-60

3. Aggarwal AN, Gupta D, Jindal SK. Diagnosis of tuberculous pleural effusion. Indian J Chest Dis Allied Sci 1999;41(2):89-100.

4. Sharma SK, Mohan A. Adenosine deaminase in the diagnosis of tuberculosis pleural effusion. Indian J Chest Dis Allied Sci 1996;38(2):69-71.

5. Malan C, Donald PR, Golden M, Taljaard JJ. Adenosine deaminase levels in cerebrospinal fluid in the diagnosis of tuberculous meningitis. J Trop Med Hyg 1984;87(1):33-40.

6. Piras M.A. and Gakis C. CSF adenosine deaminase activity in tuberculous meningitis. Enzyme. 197273;14:311-7

7. Ribera E, Martinez-Vazquez JM, Ocana I, Segura RM, Pascual C. Activity of adenosine deaminase in cerebrospinal fluid for the diagnosis and follow-up of tuberculous meningitis in adults. J Infect Dis 1987;155(4):603607.

8. Guisti G, Galanti B. Adenosine deaminase: colorimetric method. Methods of Enzymatic Analysis. 5th ed. Edited by: Bergmeyer HU. Weinheim (Germany). Verlag Chemie;1984, p.315-23.

9. Molavi A, LeFrock JL. Tuberculous meningitis. Med Clin North Am 1985;69(2):315-331.

10. Piras MA, Gakis C, Budroni M, Andreoni G. Adenosine deaminase activity in pleural effusions: an aid to differential diagnosis. Br Med J 1978;2(6154):1751-1752.

11. Ocana I, Martinez-Vazquez JM, Segura RM, FernandezDe-Sevilla T, Capdevila JA. Adenosine deaminase in pleural fluids. Test for diagnosis of tuberculous pleural effusion. Chest 1983;84(1):51-53.

12. Goto M, Noguchi Y, Koyama H, Hira K, Shimbo T, Fukui T. Diagnostic value of adenosine deaminase in tuberculous pleural effusion: a meta-analysis. Ann Clin Biochem 2003;40(Pt 4):374-381.

13. Valdes L, San Jose E, Alvarez D, Sarandeses A, Pose A, Chomon B, Alvarez-Dobano JM, et al. Diagnosis of tuberculous pleurisy using the biologic parameters adenosine deaminase, lysozyme, and interferon gamma. Chest 1993;103(2):458-465.

14. Valdes L, San Jose E, Alvarez D, Valle JM. Adenosine deaminase (ADA) isoenzyme analysis in pleural effusions: diagnostic role, and relevance to the origin of increased ADA in tuberculous pleurisy. Eur Respir J 1996;9(4):747-751.

15. Fontan Bueso J, Verea Hernando H, Garcia-Buela JP, Dominguez Juncal L, Martin Egana MT, Montero Martinez MC. Diagnostic value of simultaneous determination of pleural adenosine deaminase and pleural lysozyme/serum lysozyme ratio in pleural effusions. Chest 1988;93(2):303-307.

16. Perez-Rodriguez E, Jimenez Castro D. The use of adenosine deaminase and adenosine deaminase isoenzymes in the diagnosis of tuberculous pleuritis. Curr Opin Pulm Med 2000;6(4):259-266.

17. Chen ML, Yu WC, Lam CW, Au KM, Kong FY, Chan AY. Diagnostic value of pleural fluid adenosine deaminase activity in tuberculous pleurisy. Clin Chim Acta 2004;341(1-2):101-107.

18. Dinnes J, Deeks J, Kunst H, Gibson A, Cummins E, Waugh N, Drobniewski F, et al. A systematic review of rapid diagnostic tests for the detection of tuberculosis infection. Health Technol Assess 2007;11(3):1-196.

19. Blake J, Berman P. The use of adenosine deaminase assays in the diagnosis of tuberculosis. S Afr Med J 1982;62(1):19-21.

20. Prasad R, Kumar A, Khanna BK. CSF-ADA for the diagnosis of TBM. Ind Jour Tub., 1991;38:99-102.

21. Mishra OP, Loiwal V, Ali Z, Nath G, Chandra L, Das BK. Cerebrospinal fluid adenosine deaminase activity and C-reactive protein in tuberculous and partially treated bacterial meningitis. Indian Pediatr 1995;32(8):886889. 